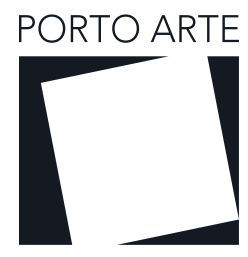

Revista de Artes Visuais

v. 24 n. 42

nov/dez 2019

e-ISSN:2179-8001

DOSSIÊ

Joaquin Barriendos ${ }^{1}$

\title{
Manchas Que Manchan: Memoria y borradura en la obra de Eugenio Dittborn²
}

Stains thatstain:Memory and erasure in the work of Eugenio Dittbom

\begin{abstract}
o
En este artículo analizaremos la aeropostalidad de Dittborn como una corporalidad en la que escritura, pintura, gráfica y fotografía se interpelan. Plantearemos el problema de las manchas, las huellas y las borraduras en tanto que indicios distópicos de cuerpos ausentes. Más en concreto, hablaremos de la aeropostalidad de Dittborn como una estrategia para 'hacer aparecer' el cuerpo de los desaparecidos, esto es, hablaremos de la pintura como confesión de lo que está ausente.
\end{abstract}

\section{Palabras clave}

Pinturas aeropostales. Borradura. Arte chileno. Dictadura. Cuerpo-escritura.

\section{Abstract}

The article addresses the work of Chilean artist Eugenio Dittborn as an embodied territory in which painting, writing, graphics and photography converge. The article characterizes his use of erasures, marks, and traces as a dystopian indication of absent bodies. More to the point, the article offers a commentary on the pictorial appearance of the disappeared body; that is, elaborates on painting as a confession of what remains absent.

Keywords

Airmail Paintings. Erasures. Chilean art. Dictatorship. Dody-writing. 


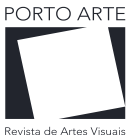

DOSSIÊ

La obra del artista chileno Eugenio Dittborn es una invitación para pensar la pintura como confesión. En sus pinturas aeropostales podemos rastrear las manchas, las secreciones, las huellas, los silencios y las borraduras de la dictadura

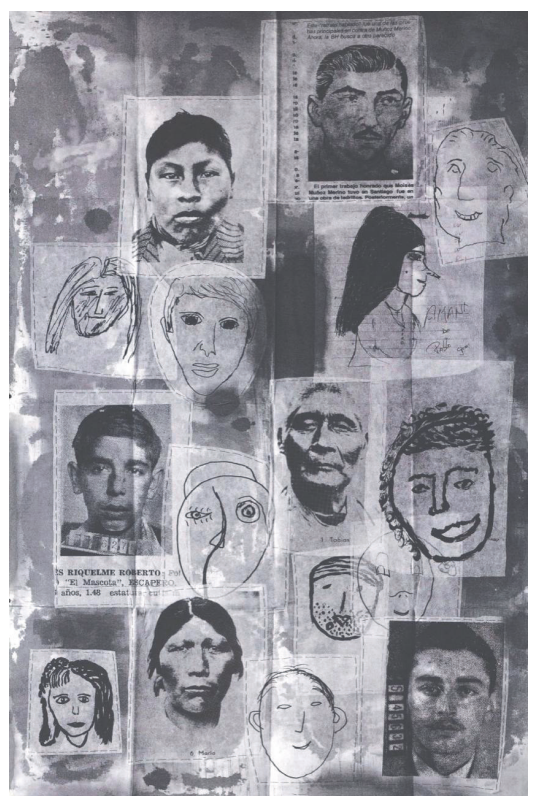

Figura 1: Pintura Aeropostal No. 93. La XII historia del rostro. Hueso muerto (1991). Fragmento. chilena. En tanto objetos a la deriva, su trabajo inaugura una suerte de poética del pliegue: una sintomatología de lo que aparece y desaparece entre los dobleces de la memoria. Si como dice Dittborn, el arte postal es un arte del secreto, sus pinturas aeropostales son secretos errantes; confesiones que secretan un tipo de verdad que la escritura no consigue referir y la fotografía no alcanza a retener.

La verdad confesa que nos acecha en las pinturas aeropostales de Dittborn es una verdad que se desdobla a través de borraduras y suturas. Una verdad que nos sitúa en el territorio de la pintura como aceptación, admisión o reconocimiento de una verdad. Al final de cuentas, confesar (com-fateri) significa admitir o reconocer en público algo; producir una verdad común. Rompiendo el orden político del secreto y el silencio, en sus pinturas aparecen los cuerpos de los desaparecidos como huella. Cuerpos-trazo que se desprenden de la violencia fundadora que los silencia, emergiendo como manchas entre sus dobleces aeropostales. [Fig. 1] Aparece la desaparición, lo des-apercibido. Se instaura un juego de apariencias y desapariciones que empuja a la memoria y al olvido hasta sus límites. Memoria como inscripción; memoria como escritura, memoria como foto-grafía. Sus pliegues aeropostales nos lanzan hacia la exterioridad del lenguaje, rompiendo el pacto sobre el que se funda la imposibilidad de hablar de los desaparecidos. Nos sitúan en el territorio en el que habita espectral -convertida en mancha- la ausencia de los cuerpos. "El sujeto sólo se hace posible-nos recuerda Ronald Kay- como negación de la mancha. De ahí el terror que habita toda mancha: ella es la marca de la ausencia del sujeto". [Fig. 2]

Formalmente, las pinturas aeropostales se componen de un

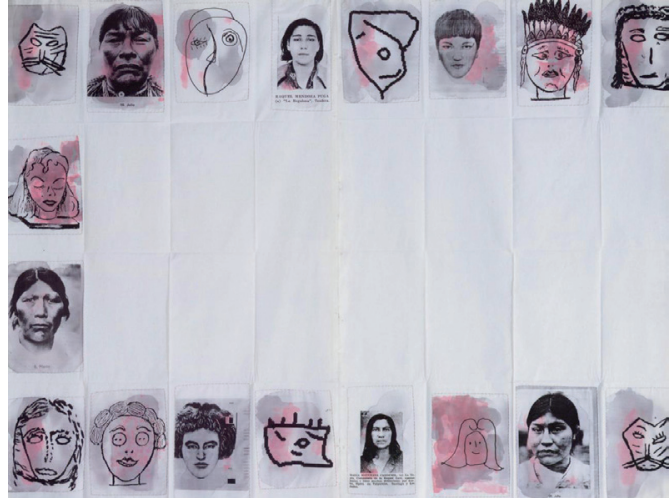

Figura 2: Pintura Aeropostal No. 119. La XIX historia del rostro (1995-96). Fragmento. cuerpo de papel cartulina o un paño de tela, el cual viaja en sobres postales cuyas dimensiones definen los pliegues y estructura de las pinturas. En medio de la dictadura chilena, el dispositivo postal sirvió a Dittborn para sortear la censura y establecer un diálogo con artistas y museos en diferentes partes del mundo. En sentido estricto, el carácter aeropostal de sus pinturas implica que llegan al lugar en el que van a ser exhibidas a través del correo y se van da la misma manera, volviéndose en su circulación objetos en permanente tránsito. Las marcas de sus desplazamientos se hacen visibles en los sellos y registros postales, convirtiéndose en una especie de cartografías portátiles. [Fig. 3] El adentro y el afuera resultan así indiferenciables. Lo que las pliega y lo que se despliega son una misma cosa. De hecho, al lado de las pinturas desplegadas se exhiben los sobres que las transportaron, pasando de ser su marco y contenedor a convertirse en contenido, parergón y paratexto. 
Pero la aeropostalidad en Dittborn es mucho más que un mero dispositivo formal de exhibición. Es la materialidad de una confesión latente, inseparable de lo que Stéphanie Decante-Araya ha definido como una patología de la memoria culpable. Las manchas de sus pinturas aeropostales funcionan como índices de cuerpos borrados; como la huella de una confesión inminente. El propio Dittborn se ha referido a ellas como el resultado de un conjunto de "secreciones líquidas del cuerpo humano depositadas en forma de derrame sobre telas".

Pinturas hechas de absorciones. Pinturas impresas por cuerpos desaparecidos. Pinturas secretadas. Para Ronald Kay -quien tempranamente detectó la presencia de borraduras orgánicas y huellas minerales en la obra de Eugenio Dittbornsus manchas aeropostales son una "impronta húmeda, la letra primordial de dicha escritura corporal; es la huella inmediata que el organismo traza desde su interior". Aludiendo a las desapariciones forzadas de la dictadura chilena, el crítico Miguel Valderrama se ha referido también a la obra de Dittborn como un cuerpo-escritura en el que aparece sintomática y paulatina la desaparición: "[e]l arte en la época de la desapa-

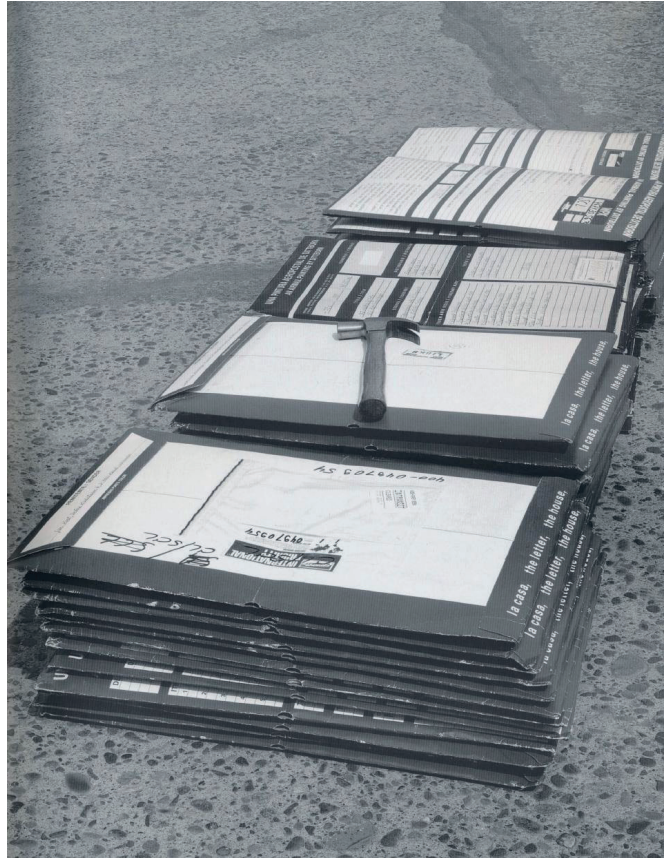

Figura 3: Cinco Pinturas Aeropostales en sobres (Cenizas Líquidas, Viajar e Historia del rostro VI, XI y XIII) olvido [...] el arte de la desaparición pareciera
un cuerpo", nos recuerda Valderrama. [Fig. 4]

En este artículo analizaremos las pinturas aeropostales de Eugenio Dittborn como territorios corporales en donde escritura, fotografía y pintura se interpelan mutuamente y la mancha emerge como el indicio de un cuerpo ausente. Lo que intentamos develar al escavar estas huellas y borraduras en sus pinturas es la posibilidad de que lo desaparecido se haga presente en ausencia. Nos interesa por lo tanto su pintura como confesión, como secreto, como fantasma. El artículo propone el término mostratura para aludir a una forma específica de mostrar el cuerpo ausente. A lo largo del texto analizaremos cómo, en su urgencia de revelar el secreto de la desaparición, pintura, fotografía y escritura se funden en un gesto corporal de inscripción.

I.

En la introducción definimos la obra de Eugenio Dittborn como una pintura confesional que camina a ciegas por el territorio de la memoria culpable y patológica del Chile dictatorial. Dicha patología explicaría por qué la desaparición aparece en el arte chileno de manera sesgada y paulatina, guiada por un lento proceso de sedimentación corporal: 
Revista de Artes Visuais

DOSSIÊ
Figura 4: Pintura Aeropostal No. 75. Si librados a su propia suerte (1989-93)
"Debo mi trabajo a la observación de secreciones líquidas del cuerpo humano depositadas en forma de derrame sobre telas, manchas que desbaratan, interfieren, desarreglan, descomponen, interrumpen y tiñen, manchas que manchan [...] Debo mi trabajo al cuerpo humano, peso muerto deportado en estado fotogénico al espacio cuadrilátero de diarios y revistas, memoria colectiva que consagra su perpetuo desamparo."

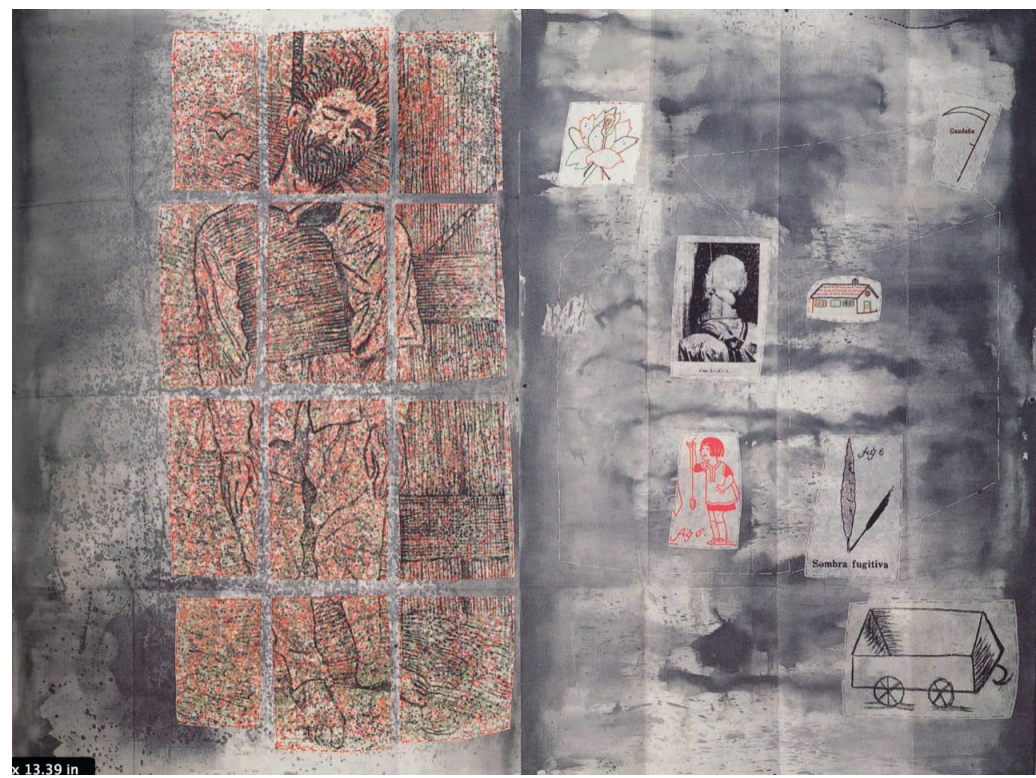

El arte en la era de la desaparición es un arte hecho de reproducciones, sedimentaciones y huellas. Un arte de cuerpos inertes, cuerpos ausentes, cuerpos reprografiados. Un arte que se juega su verdad en la posibilidad de romper el silencio de la página impresa a través del derrame de una mancha. Borraduras en la superficie de una superficie editorial en donde la tortura infringida al cuerpo desaparecido (para extraerle información) se hace extensiva al cuerpo social como totalidad. [Fig. 5] Otra vez Dittborn: "[d]ebo mi trabajo a la adquisición periódica de revistas en desuso, reliquias profanas rezagadas, en cuyas fotografías se sedimentaron los actos fallidos de la vida pública, roturas a través de las cuales se filtra, inconclusa, la actualidad."

La aparición de la mancha en el cuerpo de la pintura es la condición sine qua non para que su secreto circule como exterioridad. Lo que las pinturas aeropostales de Dittborn nos confiesan no es entonces una verdad como texto sino una verdad en forma de pliegue y borradura. Una verdad que es un lugar, que es territorio-cuerpo: el lugar de la memoria en el que la desaparición se convirtió en 
secreto. Lo que sus pinturas secretan es la imposibilidad de nombrar el cuerpo desaparecido, pero también la necesidad de revelarlo, de convertirlo en mostratura. Con la aparición del arte de la desaparición se inaugura así una poética del pliegue y una sintomatología de la mancha.

\section{II}

Iniciada en 1976, su serie Estampas Deportivas revela el carácter confesional de toda su producción aeropostal posterior. En dicha serie, emergen del agua nadadores haciendo el esfuerzo de alcanzar alguna orilla. Cabezas flotantes, sin cuerpo pero esperanzadas. Transferidos con métodos fotoserigráficos desde las páginas de revistas deportivas como LIFE hasta el cartón plegado de sus pinturas aeropostales, sus nadadores son la huella de otros cuerpos que luchan para no sumergirse en el olvido. [Fig. 6] Décadas más tarde, el propio Dittborn decodificará el mensaje de sus nadadores al recordar un rumor fantasmal que sirvió primero para mantener escondido el mensaje y después para convertirlo en confesión. En aquel fatídico 1976 su psicoanalista, Gabriel Garrido, desapreció sin dejar más huella que los rumores de que su cadáver había aparecido flotando en un canal en Santiago de Chile. Su cuerpo ausente -varado a la deriva como una fantasmagoría- se convertirá en la matriz fotográfica de una verdad escondida entre los pliegues de la serie sobre nadadores. [Fig. 7]

El crítico Roberto Merino ha leído esa serie como la confesión de su orfandad tras la desaparición de su psicoanalista. En palabras de Merino:

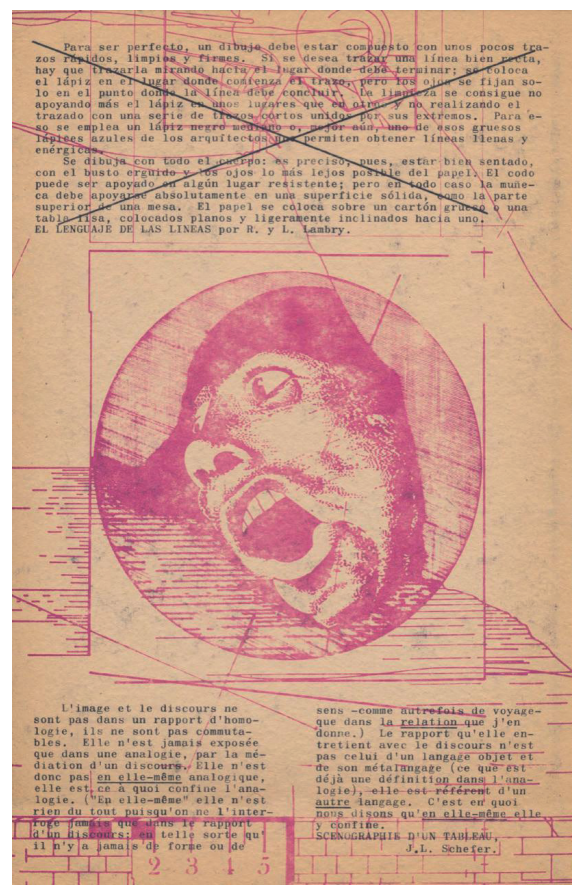

Figura 7: Fig. 7. Galería Época, Eugenio Dittborn. Dibujos. Santiago, V.I.S.U.A.L, 1976. Página interior.

\begin{abstract}
"El acuerdo de transferencia entre un terapeuta y su paciente implica que éste le confiere a aquél [...] la autoridad de un guía en un territorio, aunque propio, desconocido. Perderlo de un momento a otro equivale a quedar a medio camino en una región oscura, avanzando a tientas. Se me ocurrió entonces que las pinturas aeropostales [...] estaban, en su origen, marcadas por una experiencia de confusión y orfandad".
\end{abstract}

Si aceptamos la tesis de Merino, la pérdida de su psicoanalista habría sido suplementada en la pintura por una suerte de psicopompo visual. Como es sabido -además de compartir la raíz psique (alma) con palabras como psicoanalista o psicoanálisis- psicopompo es el nombre con el que Dante designa a Virgilio como sus ojos, como su guía para atravesar el inframundo. Guía de las almas por los infiernos en la Divina Comedia, el psicopompo de Dittborn es el que lo guía por el 


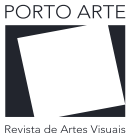

DOSSIÊ

terror de la dictadura chilena. Las borraduras y las manchas de la serie pueden ser leídas como huellas y vestigios que nos ayudan a encontrar el camino hacia la verdad en pintura; hacia la exterioridad sin texto y sin psique de la confesión. Sus manchas emergen a la superficie como cuerpos hundidos que aparecen desde el abismo de la memoria y el secreto. Como afirma Roland Kay, la mancha es aquello que acecha al sujeto, aquello que lo de-sujeta y lo deja a la deriva. Las manchas de Dittborn son manchas flotantes. Su aeropostalidad se enmarca en un arte de la urgencia y la inminencia: donde hay mancha, hubo cuerpo. "Dittborn penetra la memoria colectiva -afirma Kay- como una zona de peligro, donde a toda velocidad, con la precaución requerida, antes que sea demasiado tarde, hay que salvar algunas vidas a punto de sucumbir".

\section{III}

A partir de una fotografía de prensa del accidente sufrido por Luis Alberto Acevedo -el primer aviador chileno muerto en 1913 al caer su monoplano al río BioBio- Dittborn expande al tema del ahogado y lo conecta con la figura del aviador-poeta. Antes de emerger desde las profundidades marinas como los nadadores, sus cuerpos celestes son arrojados desde el cielo hasta la superficie de manchas de la página impresa, del periódico, del reportaje policial. Lo anterior se hace evidente en su Pintura Aeropostal $N^{\circ}$ 132. El Bleriot de Acevedo en el Biobío, en donde el aviador evoca a los escuadrones de la muerte que servían a la DINA, la Dirección de Inteligencia Nacional, para desaparecer cadáveres arrojándolos al mar o al desierto desde el aire. [Fig. 8] En esta pintura, los restos del Bleriot pilotado por Luis Alberto Acevedo aparecen claramente en la fotografía del accidente, mientras que el cuerpo del piloto se mantiene ausente, fuera del recorte fotográfico.

Sin ser plenamente consciente de ello, Dittborn intuye una conexión siniestra entre la presencia del avión y la desaparición de cuerpos: antes que registros documentales, los restos de la máquina de vuelo son manchas que suplementan el cuerpo del piloto, transmutando su condición de aviador-héroe en detenido-desaparecido. En lugar de recortar la fotografía de prensa y separarla de su texto, Dittborn incluye el relato periodístico en el que se narra con todo detalle la manera en la que fue hallado, recuperado y hospitalizado el cuerpo inerte de Acevedo. Sin presencia fotográfica, el cuerpo del piloto sólo puede encontrarse en el cuerpo impreso de la nota periodística, en el cuerpo tipográfico de la página. Cuerpo-escritura, el de Acevedo se transforma en cuerpo con/notado. A su lado, Dittborn zurce literalmente sobre el papel -como si de un cuerpo suturado se tratase- un mensaje en un trozo de tela escrito en tercera persona que sirve de pie-de-texto a la imagen y que dice textualmente lo siguiente:

"En lugar del cuerpo de Acevedo perdido en las aguas del río Bío-Bío, Dittborn iba a imprimir aquí un grupo de hombres con sombrero, buscando en vano la sombra de un avión". 


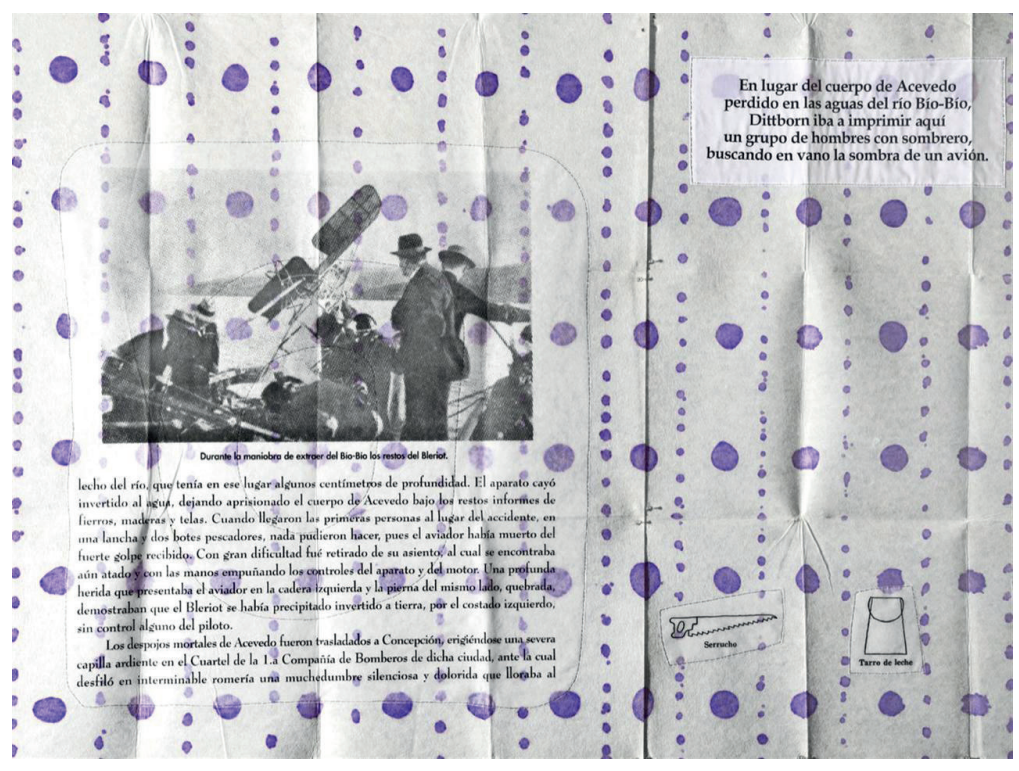

El uso del tiempo verbal en pasado de la frase 'Dittborn iba a imprimir', desborda los límites del texto suturado y lo conecta con la imagen periodística, en la que vemos efectivamente a grupo de hombres con sombrero husmeando entre los restos del Bleriot. Con este gesto, Dittborn los convierte en hombres que buscan cuerpos desaparecidos entre los escombros de la memoria.

Al transferir la fotografía del avionazo del periódico a su pintura, El Bleriot de Acevedo en el Biobío dialoga con la novela Estrella Distante del escritor chileno Roberto Bolaño. Como es sabido, Bolaño narra en su novela la vida de Carlos Wieder, un misterioso poeta-aviador quién, después escribir varios poemas de humo en el cielo de Chile, inaugura una exposición en la casa de un amigo en la que muestra fotografías de los cuerpos de otros poetas que él mismo había torturado y asesinado. Su 'acción de arte' -como la llama el propio Carlos Wieder en la novela de Bolaño- es una doble confesión: la confesión de los asesinatos en manos de un militar y la confesión de haberse apropiado del arte de avanzada para estetizar el terror. La alusión de Bolaño es explícita. Se trata de Raúl Zurita, amigo de Eugenio Dittborn y miembro del CADA (Colectivo de Acciones de Arte). La verdad en pintura (el cielo azul como lienzo del poema) despliega con toda su fuerza la potencia dual de la escritura como pharmakón: como remedio (en Zurita) y como veneno (Wieder).

\section{IV}

Con su Pintura Aeropostal no. 90 -subtitulada El cadáver, el tesoro- Dittborn regresa al problema del secreto y la orfandad. Miguel Valderrama la ha descrito como "aquella que más resiste en su secreto". Pero la orfandad de El cadáver,
Figura 8: Pintura Aeropostal No. 132. El Bleriot de Acevedo en el Biobío (2000). 


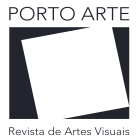

DOSSIÊ

el tesoro no es psicoanalítica, como en Estampas Deportivas, sino filial: el tema ya no es el abandono de la psique, sino la pérdida del padre y el nacimiento del hijo. Otra vez aparición y desaparición se interpelan en un régimen de trasposiciones temporales y espaciales. En El cadáver, el tesoro, Dittborn yuxtapone una foto de su hija recién nacida, Margarita Dittborn, con la fotoserigrafía del cadáver de un detenido-desaparecido tomada de la prensa. A manera de pies-de-huella o pies-de-borradura, debajo de dichas imágenes suturadas Dittborn ha incluido una serie textos que van del informe criminal a la crónica del álbum de familia. Cadáver y tesoro dialogan en esta pintura en tanto que cuerpos-escritura. La orfandad del propio Dittborn como alegoría de una escritura huérfana, de un logos que ha perdido a su padre. [Fig. 9]

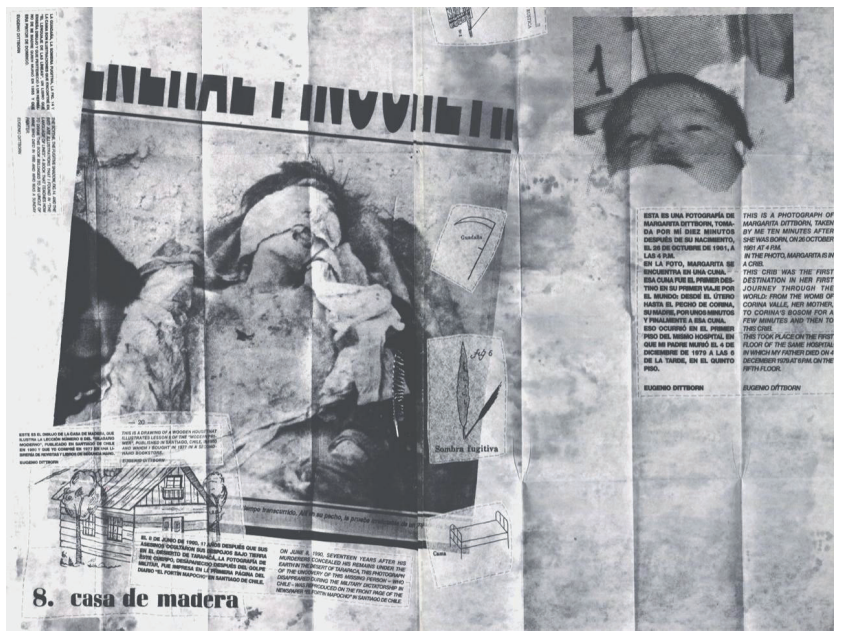

Figura 9: Pintura Aeropostal No. 90. El cadáver, el tesoro (1991).

Debajo del cadáver, Dittborn emplaza un texto en el que el artista narra la imagen de portada del diario El Fortín Mapocho, fechada el 8 de julio de 1990. Se trata del hallazgo en el desierto de Atacama del cuerpo de un detenido-desaparecido, asesinado diecisiete años atrás por el golpe militar. Momificado y convertido huella de la dictadura, el cadáver reaparece como confesión. Cadáver desenterrado dos veces, primero de la tierra árida del desierto, después de la superficie manchada de las páginas del periódico. A su lado encontramos la foto de su hija, tomada al nacer en el mismo hospital en el que habría muerto el padre de Dittborn en 1979. Enmarcada por manchas, recortes y textos suturados, la imagen de la recién nacida suple la ausencia del padre y le reintegra la vida al militante asesinado. Muerte y vida atadas a un cuerpo-escritura, a una mancha que se pliega. Debajo de la imagen, Dittborn nos ofrece un relato de familia: la crónica del nacimiento de su hija y del deceso de su padre. La precisión de las horas y fechas de nacimiento y muerte le otorgan al álbum de fotos de familia una mirada clínica. Sin fijarlo al texto, el cadáver del detenido-desaparecido se reintegra como familia al cordón umbilical que une el nacimiento de Margarita con la muerte del padre en plena dictadura.

\section{V.}

La re-familiarización del desaparecido que Dittborn opera en El cadáver, el tesoro se repetirá en otras pinturas aeropostales, sobretodo en aquellas en las que el artista yuxtapone dibujos de personas anónimas dibujadas por la mano de su hija con rostros de criminales, locos y personas abyectas salidas de las páginas de revistas policiales. [Fig. 10] En la misma lógica reintegradora del cadáver-tesoro, estos rostros despliegan toda su potencialidad como manchas.

En lugar de deslavarlos, Dittborn mantiene los rostros como manchas, como manchas que miran, supuran y revelan. Los reconoce como manchas manchadas, como manchas 
que manchan. Convertido él mismo en una mancha, Dittborn dialoga con los cuerpos desaparecidos a través de sus borraduras. El manchar como un ejercicio muscular de la mirada dialogada. Pintura, escritura, fotografía se reintegran como índices de la desaparición y la tortura. Su poética del pliegue resignifica la mancha sin convertirla en monumento. "[L]a compulsión de borrar la mancha -afirma Rolando Kay- obedece a la imperiosa necesidad de obliterar las señas de la presencia precultural del hombre".

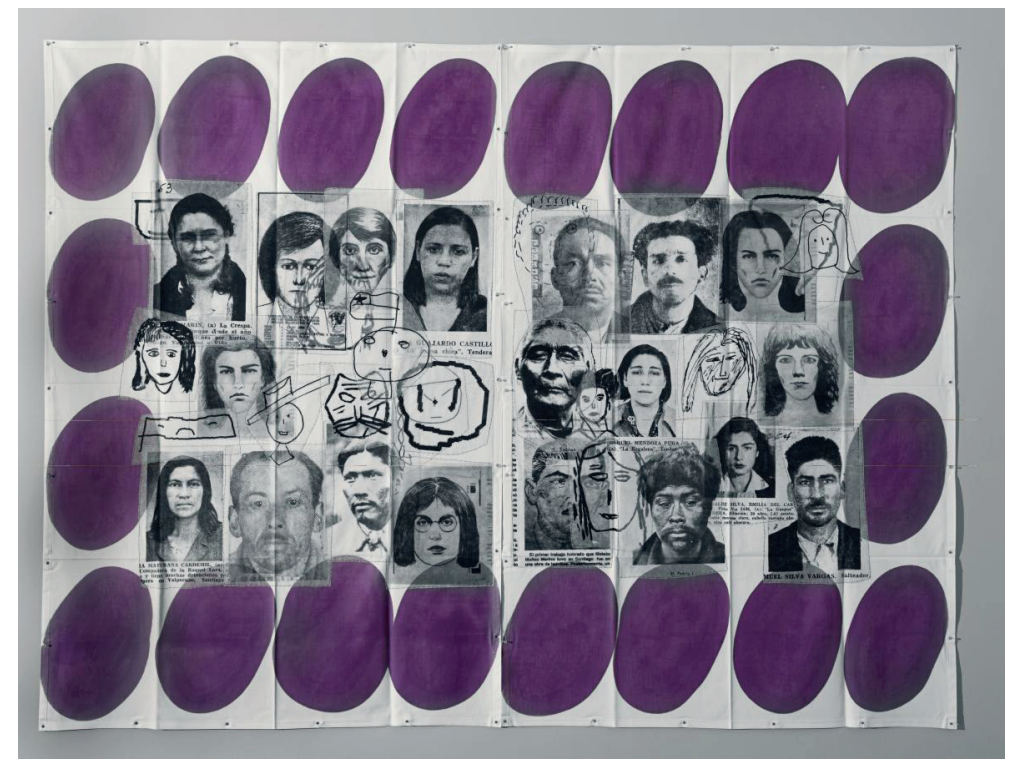

En lugar de borrar las manchas, Dittborn las sutura, las vuelve un pliegue de la memoria; las inscribe en el cuerpo de la pintura como la tortura se escribe en el cuerpo del torturado. El viaje, el desierto de Atacama, los naufragios. Mar y cordillera como tumbas. En la urgencia de revelar el secreto de la desaparición, las pinturas aeropostales de Eugenio Dittborn se convierten en gestos corporales de inscripción. No tenemos más remedio que entregarnos a ellas con la franqueza y apertura de nuestra mirada. Si la escritura se ve obligada a volverse cuerpo para poder ser secretada, el cuerpo-desaparecido sólo puede regresar al lenguaje como borradura y confesión: como mostratura. Sólo puede secretarse como mancha desde el interior de un cuerpo-ausencia. De la misma manera que la luz se escribe mineralmente sobre el papel fotográfico, en las pinturas aeropostales de Dittborn los rostros-sin-cuerpo y los cuerpos-sin-rostro habitan en la página plegada, editados por una escritura corporal arcaica, anterior al lenguaje.
Figura 10: Pintura Aeropostal No. 128. La XXIII historia del rostro. (1999). 
PORTO ARTE

DOSSIÊ

\section{REFERÊNCIAS}

Kay, Ronald, Del espacio de acá. Señales para una mirada americana. Santiago: Editores Asociados, 1980.

Merino, Roberto, Fugitiva. El trabajo de Eugenio Dittborn. Santiago de Chile, Fundación Gasco, 2005.

Valderrama, Miguel, La aparición paulatina de la desaparición en el arte. Fragmentos de una historia del secreto. Santiago de Chile, Palinodia, 2009, p. 23. 


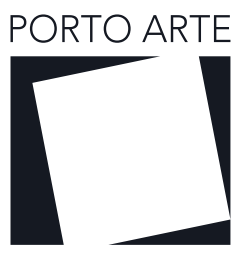

Revista de Artes Visuais

v. 24 ก. 42 nov/dez 2019 e-ISSN:2179-8001.

DOSSIÊ

\section{Joaquin Barriendos}

Es doctor en Historia y Teoría del Arte por la Universidad de Barcelona. Ha sido profesor en el Departamento de Estudios Latinoamericanos de la Universidad de Columbia en Nueva York e investigador del Instituto Nacional de Historia del Arte de París, de la Universidad de Barcelona y del Programa en Estudios de Museos de la Universidad de Nueva York. Actualmente es investigador de tiempo completo de la Universidad Nacional Autónoma de México en donde imparte clases en el Posgrado en Historia del Arte. Escribe sobre arte, política y teoría de la cultura y es curador de exposiciones. Entre sus últimos libros se encuentran Juan Acha. Despertar Revolucionario (2017) y Archivos Fuera de Lugar (2018).

Como citar: BARRIENDOS, Joaquin MANCHAS QUE MANCHAN: Memoria y borradura en la obra de Eugenio Dittborn. Porto Arte: Revista de Artes Visuais. Porto Alegre: PPGAV-UFRGS, nov-dez, 2019; 